\title{
CIUDAD Y CIUDADANÍA: \\ dos ideas en debate
}

Jürgen Golte

\section{Resumen}

El primero y más grave de los problemas es el concepto mismo de "ciudad". Sabemos muy bien que la palabra hoy en día se refiere a cualquier aglomeración de personas que no trabajan primariamente en la producción directa de alimentos.

Palabras claves: ciudad, ciudadanía, Lima.

\section{Abstract}

The main and most serious problem is the mere concept of "city". We very well know, nowadays that word refers to any kind of crowded gathering of people who doesn't primarily work in the direct production of food.

Key words: city, citizenship, Lima.

\section{La ciudad, las ciudades y su Hinterland}

Con la idea de ciudad, se hace necesario el recurso a otro concepto que comúnmente se llama Hinterland (prometo que será la única palabra en alemán que voy a utilizar). Es que el Hinterland, la tierra que está detrás de las murallas de la urbe es un espacio central para la definición de las características de la ciudad misma. Así como la ciudad se define por la ausencia de la producción directa de alimentos, tiene que existir un dispositivo que permite que los habitantes de la ciudad logren el acceso a los bienes que se producen en la "tierra de atrás". Este modo de interacción entre la ciudad y su tierra de atrás es lo que nos permite definir con algo más de claridad lo que distingue una ciudad específica de otras que llevan el mismo apelativo. 
Resulta obvio que el concepto de ciudad es sumamente vago y dice poco sobre una ciudad específica. Así que dentro de esta categoría tenemos Nueva York, Londres, París, Moscú, Tokio, Beijing y, cómo no, Huancayo, Sicuani, Huacho y La Meca, para nombrar solamente unas cuantas. Dos tercios de la población global viven hoy en ciudades. Necesitamos, para poder hablar con algo más de propiedad, categorías más específicas para poder entender lo que hablamos.

Voy a mencionar solo algunos tipos, que ya existen desde hace muchos siglos para mostrarles la utilidad de tal ejercicio.

Un primer tipo surge muy tempranamente: es lo que llamamos "la ciudad palacio". La ciudad palacio se define por el hecho de que su habitante principal es el ocupante de un centro de poder que abarca tanto a la ciudad como a la tierra de atrás. Gracias a su poder y su función de dominar ambos espacios; los bienes necesarios para mantener el palacio y todos los que dependen de él directa o indirectamente, es decir, los habitantes de la ciudad, llegan a esta.

Es el poder que logra que la gente del entorno, de la tierra de atrás, entregue los bienes necesarios como tributo al palacio. Muchas veces no solo son los contribuyentes de alimentos y otros bienes, en especial materia prima para la edificación de la urbe y para los artesanos que sirven al palacio, sino también la fuerza de trabajo necesaria que construye las murallas, los palacios, los parques y las avenidas. Los habitantes de la ciudad a su vez son súbditos del soberano, son los miembros de su corte, su burocracia, sus sirvientes, pero también los que transforman los bienes acarreados del campo en objetos de consumo para toda la población urbana. En el Perú antiguo había famosas "ciudades palacio" como Chan Chan, la capital del estado Chimú, cuyos restos podemos admirar hasta hoy.

Prácticamente a la par con la "ciudad palacio" surge otro tipo: "el centro de intercambio". Sus habitantes son los que organizan el intercambio de bienes o permiten que este acontezca en un "espacio urbano" entre los diversos grupos sociales que habitan la "tierra de atrás". Los habitantes de la ciudad no tienen acceso a estos bienes gracias a su poder, sino básicamente gracias a su función en el intercambio de ellos. A cambio de su servicio se les entrega una parte de ellos.

Es interesante en este contexto que ciudades de este tipo surgen muchas veces como lugares vacíos. Ahí la gente diversa de un espacio deja de lado los conflictos que pueden tener entre ellos para poder organizar un intercambio que por razones múltiples (acceso diversificado a materias primas, productos primarios de los grupos sociales de la tierra de atrás) es una condición para su existencia. Hay ciudades de este tipo en el Perú antiguo, como Pikillaqta y Viracochapampa, pero no voy a nombrar más para no meterme en discusiones que en este momento no son útiles.

Nuevamente diferente al último tipo es otro que ha resultado de importancia primordial en los últimos siglos si bien data, como los otros tipos ya mencionados, de los albores del desarrollo civilizatorio en el mundo hace unos nueve a diez mil años. Llamamos a este tipo de ciudad "ciudad de productores". Sus habitantes producen bienes cuyo uso resulta ventajoso para los de la tierra de atrás, quienes por lo tanto recurren a la ciudad de productores para adquirir tales bienes a cambio de sus propios productos. Estos bienes, entonces, se convierten en bienes de consumo y también de 
materia prima para los productores urbanos. La combinación entre ciudad de productores y su hinterland genera una dinámica especial.

La "ciudad palacio", en síntesis, extrae riqueza de su hinterland. En este sentido, contribuye a su estancamiento y de ninguna manera a su crecimiento.

La ciudad de intercambio puede facilitar cambios técnicos y de bienestar en su binterland pero generalmente no contribuye a estos, sino simplemente los facilita al dar a los habitantes del binterland insumos que les son útiles para mejorar las técnicas de producción.

En contraste, la ciudad de productores por lo general produce bienes que resultan ser factores de producción, en especial herramientas. Estas herramientas, por ejemplo las de labranza para los agricultores del hinterland, contribuyen a un aumento de la productividad del trabajo en el binterland. Su producción y el excedente de ella pueden crecer. El hinterland por lo tanto desarrolló más capacidad para el intercambio. Este crecimiento de la capacidad a su vez permite que la "ciudad de productores" crezca ya que se ha generado más oferta en el hinterland. En otras palabras: el binomio "ciudad de productores y su binterland pueden crecer juntos, el crecimiento de uno condiciona al crecimiento del otro.

Quizá, valga la pena mencionar que "ciudades de productores" no son tan frecuentes en el desarrollo civilizatorio de los Andes, en comparación con el Viejo Mundo, porque en los Andes el desarrollo de la agricultura al no disponer de animales de tracción, como en el Viejo Mundo, no dependía tanto de herramientas acoplables a animales de tracción, sino tomó un rumbo propio por medio de una transformación constante de la naturaleza, es decir, domesticación de plantas y domesticación del ambiente.

Han existido otros tipos de ciudad, por ejemplo la "ciudad de peregrinaje", en la cual los habitantes del hinterland llevan el sustento a la urbe como ofrendas, como dádiva para las divinidades veneradas. Estas ciudades como La Meca, Fátima, Santiago de Compostela, son más frecuentes de lo que se supone. También las hay en el Perú Antiguo, por ejemplo Pachacamac. Otro tipo son "ciudades de transmisión de conocimientos", quizá la más famosa de ellas sea Alejandría, pero especialmente hoy en día abundan. Hay muchas ciudades que simplemente imparten conocimientos, por ejemplo ciudades en la cuales la universidad es el "centro de actividad urbana", y viven de la contribución de sus usuarios. Pero no queremos ahondar en una tipología exhaustiva. Es cierto que los tipos expuestos se refieren a tipos que existieron con mucha nitidez en el pasado, hoy en día el panorama es bastante más complejo porque especialmente las megaciudades son multifuncionales y no siempre se dejan ubicar en una tipología basada sobre los tipos de ciudad que ya se formaron en la antigüedad. Sin embargo, esto no significa que se hayan convertido en una tipología inútil, sino en muchos casos bastante pertinentes para comprender la particularidad, incluso de las megaciudades que hoy encontramos con cada vez mayor frecuencia en el mundo. 


\section{La ciudadanía}

Con los tipos expuestos se puede argumentar ya con más propiedad sobre la ciudadanía. Es que solo en las ciudades de intercambio y las ciudades de productores surgen ciudadanos que requieren de un tipo de autoorganización para dar orden al conjunto social que habitan. Solo en ellas los habitantes definen las instituciones de su ordenamiento y las reglas con las cuales interactúan entre ellos y también en relación con los habitantes del hinterland. Ellos son los que desarrollan las instituciones de democracia y autogobierno, ellos desarrollan leyes para administrar el bien común. Y esto, por si acaso, mucho antes del surgimiento de los Estados-nación en los siglos XVII y XIX. Ellos son visiblemente diferentes a los habitantes de una "ciudad palacio". Ahí los habitantes dependen del palacio, son la burocracia del palacio, y en el mejor de los casos de independencia relativa, son mercaderes o artesanos que producen o importan bienes para los habitantes del palacio. En una "ciudad palacio" la normatividad emana del centro de poder y no es una especie de acuerdo entre los habitantes para que crear un orden en su asentamiento.

Históricamente se puede ver a partir de la Edad Media centroeuropea, por ejemplo, una división clara entre ciudades palacio por un lado y ciudades de mercaderes y productores independientes por otro. Su desarrollo, durante mucho tiempo paralelo, conduce finalmente a una revolución de las formas de producción e intercambio, el desarrollo de las manufacturas e industrias y los medios de transporte, y un enfrentamiento cada vez mayor con las ciudades palacio. Este conflicto finalmente se expresa en las "revoluciones burguesas", como la Revolución francesa, dirigidas contra el poder de las ciudades palacio, es decir, los señores feudales, los reyes y emperadores. Con estas revoluciones, la institucionalidad de las ciudades productivas es ampliada para los Estados-nación nacientes. En ellos, su organización administrativa, la división de poderes y la legislación correspondiente surge lo que se conoce como ciudadanía. En última instancia esta es la conciencia de cada habitante que él es el actor central de la sociedad, y la relación entre él y la sociedad es regulada mediante leyes a las cuales puede recurrir para definir su ubicación en la totalidad. La igualdad de todos los miembros de la ciudad y la conciencia de los derechos que emanan de esta igualdad es en el centro de lo que se llama ciudadanía.

Quizá, y para hacer más visible la historicidad del concepto, habría que hacer hincapié en el hecho de que en este sentido la historia europea, y la de los países que son frutos de su expansión, es particular. Louis Dumont en sus escritos sobre la India nos ha hecho ver que la historia europea en este aspecto difiere de muchas de las otras sociedades. Su división entre sociedades holistas, que describe en su obra Homo Hierarchicus, y las particularidades europeas especialmente después del siglo de las luces - a las cuales se refiere en su obra posterior Homo Aequalis- ilustran este punto de manera muy clara. Su distinción entre las sociedades holistas y las individualistas sigue siendo importante para entender los ritmos diversos de desarrollo de sociedades incluso a principios del siglo xxI. 


\section{Lima como ciudad y “ciudadanía” como meta utópica}

Resulta largo este excurso histórico y la tipología de ciudades. Pero era una introducción necesaria para poder debatir el tema "La ciudad y su ciudadanía" en el contexto concreto en el cual nos encontramos. La primera pregunta es entonces: cla ciudad de Lima a qué tipo de ciudad corresponde? Si bien es cierto que hoy en día la mayoría de las ciudades no corresponde a tipos ideales, resulta relativamente fácil determinar que la ciudad de Lima nace como una ciudad palacio. Es la sede del Virrey que gobierna el espacio colonial y vive de las rentas que produce su binterland, es decir, el Virreinato del Perú. Se puede debatir sobre lo que pasa después de la "independencia". No quiero entrar en los detalles del debate pero resulta visible que Lima sigue siendo palacio y sigue viviendo de las rentas que produce el país. Es decir, que la República del Perú haya adoptado una constitución derivada del modelo de un Estado-nación europeo después de la victoria sobre el palacio (de Versalles en este caso) es un símbolo pero no se convierte en eje gobernante de la realidad social cotidiana.

Si uno quiere constatar esto incluso hoy, casi dos centurias después, hay que plantearse simplemente la pregunta: ¿dónde se genera la riqueza en el Perú de hoy? Es decir la misma riqueza que alimenta los centros comerciales, las autopistas en el ámbito urbano, el consumo de automóviles de lujo, las construcciones palaciegas que hay por algunas partes, y probablemente las cuentas bancarias abultadas de una parte la población. La respuesta es difícil a primera vista: ¿dónde están los centros de producción que producen los valores para la adquisición de estos bienes? Mal o bien hay que salir de la ciudad, en parte a lugares bien apartados y recónditos: ahí tenemos la agricultura comercial, tanto la lícita como la ilícita, la pesca, la minería. Cuando vemos las cifras de exportación estos dan una idea clara. Ahora bien, pregúntense cómo la riqueza se traslada de sus lugares de producción a Lima. Cómo una buena parte de la producción mencionada se encuentra en manos de capital foráneo, no es el plus valor de una burguesía local, a la usanza europea, el que se convierte en fondo de consumo. Es centralmente la renta. La riqueza de la ciudad se basa sobre la renta que se cobra sobre la producción de riqueza en todo el país. Es básicamente el Estado y los tenedores de él los que la redistribuyen. Lima tiene la fama de ser centralista, pero si vemos los rubros de producción de riqueza estos no parecen ser muy centralizados. Es el gasto de la renta lo que está centralizado. La renta es lo que crea la aparente opulencia de Lima en algunas partes. Es decir, expresado en los términos que utilicé para describir la ciudad palacio: hay un flujo de bienes del binterland a Lima que solo encuentra su contraparte en el ejercicio de poder desde el centro hacia la periferia productiva.

Claro, se puede decir que no todos los habitantes de Lima gozan directamente de estas rentas. Es cierto, pero es igualmente cierto que lo mismo vale para las ciudades palacio antiguas. Hay un sistema de redistribución de la renta que crea una estratificación de acuerdo al monto que recibe un tenedor de poder. Y, es cierto, hay una población muy amplia que produce bienes de consumo y servicios. Pero ahí hay que fijarse bien. El mercado de estos bienes de consumo se ubica claramente en Lima. Observen por ejemplo la infraestructura vial del país, ya con un poco de maldad les 
puedo hablar de la autopista de varios carriles que conduce a los balnearios del sur o una que va hacia Vitarte. Ahí termina. Las fuentes de riqueza están más allá. Es decir, la infraestructura no está adecuada a una estructura productiva, sino a una estructura consumista. En este sentido, la producción y la intermediación limeña son comparables a los artesanos e intermediarios en las antiguas "ciudades palacio". Babilonia es el centro del gasto de la renta, no el centro de producción.

Si resulta cierto que Lima en "esencia" sigue siendo una ciudad palacio tenemos que preguntarnos seriamente si el modelo de ciudadanía desarrollado para ciudades y posteriormente Estados-nación es algo realmente aplicable para la población limeña. Dejo al criterio de cada uno la respuesta a la preguntas si la ciudad y sus habitantes que viven en condiciones con distancias abismales en cuanto a poder económico, político y su capacidad de invocar su "igualdad de derechos" frente a una justicia independiente y ejercida bajo un criterio de igualdad, es una perspectiva realista. La invocación de una ciudadanía como se desarrolló en las ciudades de productores y posteriormente en los Estados-nación originarios parece altamente utópica. No es ningún secreto que las instituciones de división de poderes son altamente frágiles. Invocar un derecho de ciudadano puede ser extremadamente problemático.

Es más, efectivamente hay un aparato político "formal" que muestra formas derivadas de las constituciones de los Estados-nación decimonónicos. Pero igualmente no es ningún secreto para la población limeña que hay un manejo de poder "informal" que se caracteriza más por una superposición jerarquizada de redes de poder. Ambas formas de manejo de poder, si bien están profundamente imbricados, corresponden a formas de "derechos" muy diferentes.

Podemos asumir entonces que ciudadanía es una meta utópica. Resulta más utópica aún porque no se trataría solamente de imponer la ley de la "igualdad de derechos" dentro de la ciudad palacio, sino también entre la ciudad y su hinterland. Creo que no vale tanto la pena enumerar la gran cantidad de razones que hacen pensar que no nos encontramos muy cerca de esta situación.

¿Por qué entonces prestarse el concepto de la ciudadanía en una ciudad que dista en muchos sentidos de una sociedad que permitiría su ejercicio real? Creo que hay varias razones poderosas para no dejar de lado la utopía. Una surge del hecho que tanto la ciudad de Lima como el país no se dejan subsumir fácilmente bajo una regulación "palaciega". Efectivamente, en la ciudad de Lima han crecido de manera importante sectores más comparables con las ciudades de productores y de intermediarios. En este sentido, hay voluntades políticas y sociales diversas, contradictorias entre ellas, que por lo pronto se expresan en una conflictividad creciente. Es que las reglas de la ciudad palacio no se condicen muy bien con las reglas que han surgido en ciudades de productores e intermediarios.

El hinterland de una ciudad de productores tiene otra dinamicidad que el de una ciudad palacio. Así que también a nivel de todo el Estado se dan contradicciones a nivel político. También ahí una fracción gozaría de más capacidad de desarrollo que otra vinculada al modelo de la ciudad palacio. Modelos políticos contradictorios pueden entrar en conflicto. Mal o bien el modelo de la ciudadanía, del Estado de derecho, alberga la posibilidad de un manejo ordenado de la situación de conflicto. Esta es 
una de las razones, por las cuales, a pesar de ser utópico, resulta urgente insistir en el desarrollo de una conciencia de ciudadanos.

La segunda razón no es menos importante: cada vez más los Estados-nación decimonónicos, aunque sean solamente remedos de ellos, dejan de tener una cara "realmente existente". Cada vez más los habitantes del mundo se ven en situaciones en las cuales su condición es determinada fuera del ámbito del Estado al cual están adscritos. La actual crisis financiera global es un buen ejemplo de ello. La población mundial sufre sus consecuencias. Hay que estar consciente que aún sigue en desarrollo. Uno de los principales problemas en manejar esta crisis y crear una institucionalidad que permita limitar las posibilidades de una repetición sería precisamente el hecho de que las interrelaciones económicas causantes se ubican en espacios que escapan del control de los Estados-nación y por lo tanto, de los ciudadanos. Es decir, los afectados por la crisis aunque vivan en sociedades donde la idea de ciudadanía no es simplemente utópica no pueden decidir sobre las condiciones de su vida porque las realidades económicas y financieras mundiales no están bajo su control de ciudadanos.

Ahí está el punto de encuentro: los ciudadanos utópicos peruanos frente a esta problemática se encuentran con ciudadanos utópicos mundiales que claman por una ciudadanía mundial que pueda dar a los habitantes del planeta derechos de ciudadanía frente a fuerzas económicas que escapan de su control. Ciudadanía, hoy entonces, es parte de un clamor de los habitantes del mundo para crear una institucionalidad global que otorgue derechos a los ciudadanos del mundo. Esto, como dijimos, es la segunda razón por la cual hay que crear conciencia de ciudadanía. Es que el mundo requiere que sus habitantes desarrollen una conciencia de la necesidad de una institucionalidad en la cual puedan reclamar y ejercer derechos y, por lo tanto, una voz en el control de la situación en la cual viven ellos y vivirán sus hijos. Esto vale para todos, peruanos y no peruanos.

Con esto quiero regresar al problema de la ciudadanía en la ciudad de Lima. Lima es una ciudad muy heterogénea. Por un lado sigue siendo una ciudad palacio con sus consecuencias para el establecimiento de un orden social que realmente permita no solo la creación de una ciudadanía "nominal". Sin embargo, especialmente a partir de la segunda mitad del siglo xx ha surgido en Lima a partir de la economía de los inmigrantes un espacio económico que se escapa cada vez más de las características palaciegas y se acerca al modelo de la ciudad de intermediarios y de productores. Esta parte de la población probablemente pudiera desarrollarse más apropiadamente con un modelo de ciudad con ciudadanía realmente existente. Una ciudad en la cual hubiera reglas claras para su desenvolvimiento, y como no, también reglas que reforzarían los ámbitos económicos por ellos.

Visto desde las posibilidades de un desarrollo futuro de tal institucionalidad y la conciencia de los habitantes que una institucionalidad de este tipo podría crear las condiciones para su desarrollo sostenido, esto resultaría ser ante todo un factor de apoyo a una conciencia política que reclamaría derechos de ciudadanía y una institucionalidad que corresponda a ella. En cuanto a las voluntades políticas y un reclamo de una institucionalidad que corresponda a una ciudadanía hay un desarrollo 
muy pobre, básicamente ligado a un sector intelectual. El estudio de Yusuke Murakami "Perú en la era del chino: la política no institucionalizada y el pueblo en busca de un salvador", ha demostrado esto muy bien para los sectores menos favorecidos de la ciudad. Pero son ellos al mismo tiempo los que apoyan la conversión de la ciudad palacio en ciudad de intermediarios y productores. La idea de una ciudadanía y una institucionalidad correspondiente podría dar forma a la formulación de proyectos políticos. Si pensamos en un futuro político de Perú cercano con el doble de habitantes que tiene en este momento será necesario generalizar la idea de una ciudadanía posible que dejaría de ser utópica mediante la creación de una institucionalidad correspondiente. Por cierto, que esto es una utopía política hoy pero probablemente en el futuro se volverá cada vez más una necesidad.

\section{BIBLIOGRAFÍA}

ADAMS, McCormick

1966 The evolution of urban society: early Mesopotamia and preshispanic Mexico. Chicago: Aldine.

ADAMS, Norma y Nestor Valdivia

1991 Los otros empresarios: Ética de migrantes y formación de empresas en Lima. Lima: Instituto de Estudios Peruanos. (Colección mínima.

ADLER LOMNITZ, Larissa

1994 Redes Sociales, cultura y poder: ensayos de Antropología Latinoamericana. México, D. F.: Flacso México.

ALTAMIRANO, Teófilo

1985 Migrantes campesinos en la ciudad: Aproximaciones teóricas para el estudio. Lima.

ALVÁREZ, Sonia E., DAGNINO, Evelina y ESCOBAR Arturo (eds.)

1998 Cultures of Politics - Politics of Culture: Re-visioning Latin American Social Movements. Boulder, Colo.

ARROYO, Eduardo

1994 El centro de Lima: Uso social del espacio. Lima: Fundación Friedrich Ebert.

BALBI, Carmen Rosa (ed.)

1997 Lima: Aspiraciones, reconocimiento y ciudadanía en los noventa. Lima: Fondo Editorial de la PUCP.

BLUM, Volkmar

1999 Nation und Gesellschaft im Mittleren Andenraum: Exklusion und Inklusion, Rassismus, Ethnizität und Hybridität. [Dr. phil. habil., Berlin, Freie Universität Berlin, FB Politik und Sozialwissenschaften der FU Berlin].

BONILLA, Heraclio

1972 La independencia en el Perú. Lima: Instituto de Estudios Peruanos.

BROMLEY, Juan y BARBAGELATA, José

1945 Evolución urbana en la ciudad de Lima. Lima: Consejo Provincial de Lima. 
DAMONTE VALENCIA, Gerardo

1994 Componentes de la cultura urbana en el Perú. Anthropología del Departamento de Ciencias Sociales 11(11): 283-307.

DEGREGORI, Carlos; LYNCH, Nicolás y BLONDET, Cecilia

1986 Conquistadores de un nuevo mundo. De invasores a ciudadanos en San Martín de Porres. Lima: IEP.

DEGREGORI, Carlos Iván

1993 "Identidad étnica. Movimientos sociales y participación política en el Perú". en: Adrianzén et alii (ed.), Democrácia, etnicidad y violencia política en los países andinos; pp. 113-136. Lima: IFEA, IEP.

DIETZ, Henry Avery

1998 Urban Poverty, Political Participation, and the State: Lima 1970-1990. Pittsburgh: University of Pittsburgh Press. (Pitt Latin American Series).

FLORES GALINDO, Alberto

1991 La ciudad sumergida: aritocrácia y plebe en Lima. Lima: Ed. Horizonte.

FRANCO, Carlos

1991 “Exploraciones en 'otra modernidad'. De la migración a la plebe urbana. en: Enrique Urbano (ed.), Modernidad en los Andes; pp. 189-227. Cusco: Las Casas.

GOLTE, Jürgen y ADAMS, Norma

1987 Los Caballos de Troya de los Invasores. Estrategias Campesinas en la Conquista de la Gran Lima. Lima: IEP.

GOLTE, Jürgen

1995 “Nuevos actores y culturas antiguas". en: Julio ed. Cotler (ed.), Peru 19641994. Economía, sociedad y politica; pp. 135-148. Lima: IEP.

1999 Campo y ciudad: los intereses cambiantes de los antropólogos. Lima.

1999b Redes étnicas y globalización. XIII Reunión anual de Etnología, (La Paz). MUSEF.

GONZÁLEZ CUEVA, Eduardo

1995 "Ciudades paralelas: Una investigación sobre el imaginario urbano" en: Eduardo González Cueva, Rosa Mendoza García, Martín Santos Anaya y (Autoren nicht Hg.!) (eds.), Ciudad de jóvenes: Imágenes y cultura; pp. 11-39. Lima: PUC. (Temas en sociología 5)

GROMPONE, Romeo

1991 El velero en el viento: Política y sociedad en Lima. Lima: IEP. (Serie urbanización, migraciones y cambios en la sociedad peruana 12).

GUERRERO, Andrés

1993 "De sujetos indios a ciudadanos étnicos: de la manifestación de 1961 al levantamiento indígena de 1990" en: Adrianzén et alii (ed.), Democrácia, etnicidad y violencia politica en los países andinos; pp. 83-102. Lima: IFEA, IEP.

GUPTA, Akhil y FERGUSON, James

1992 Beyond 'Culture': Space, Identity and the Politics of Difference. Cultural Anthropology 7(1): 6-23.

HOLSTON, James y APPADURAI, Arjun

1996 Cities and Citizenship. Public Culture 8: 187-204. 
HUBER, Ludwig

1997 Etnicidad y economía en el Perú. Lima: Instituto de Estudios Peruanos. (Documento de trabajo 83).

IZIGA NUÑEZ, Roger

1993 Sociología, movimientos sociales y espacio urbano: "El caso de Lima metropolitana". Lima: Universidad Nacional Mayor de San Marcos.

JOSEPH, Jaime

1999 Lima, magaciudad, democrácia, desarrollo y descentralización en sectores populares. Lima: Alternativa.

LEEDS, Anthony

1994 Cities, Classes, and the Social Order. Roger Sanjek (ed.). Ithaca, NY; London: Cornell University Press.

MACASSI, Sandro

1999 "Jóvenes y cultura política masiva. Vivencias ciudadanas desde los informativos" en: Aldo y Marcel Valcárcel Panfichi (ed.), Juventud: sociedad y cultura. Vivencias ciudadanas desde los informativos; pp. 351-392. Lima: PUC, UP, IEP.

MATOS MAR, José

1984 Desborde popular y crísis del Estado. El nuevo rosotro del Perú en la década de 1980. Lima: IEP.

Mendoza García, Rosa

1995 "Siempre me lo dicen: Mandato generacional y movilidad social en hijos de migrantes” en: Eduardo González Cueva, Rosa Mendoza García, Martín Santos Anaya y (Autoren nicht Hg.!) (eds.), Ciudad de jóvenes: Imágenes y cultura; pp. 41-70. Lima: PUC. (Temas en sociología 5).

MENESES RIVAS, Max

1998 La utopia urbana: El movimiento de pobladores en el Perú. Lima: Brandon Enterprises.

MERINO, Francisco

1999 "La familia y la construcción de la cultura del trabajo en jóvenes limeños: el caso de un grupo de estudiantes de computación e informática de tres institutos superiores tecnológicos” en: Aldo y Marcel Valcárcel Panfichi (ed.), Juventud: sociedad y cultura; pp. 49-92. Lima: PUC, UP, IEP.

MÉNDEZ, Cecilia

1996 Incas sí, indios no: not on Peruvian Creole nationalism and its contemprary crisis. Journal of Latin American Studies 28(I): 197-225.

MIEROOP, Marc van de

1997 The ancient Mesopotamian City. Oxford: Clarendon Press.

MORRIS, A. E. J.

1993 History of Urban forms before the industrial revolutions. New York.

NUGENT, Guillermo

1992 El laberinto de la choledad. Lima: Fundación Friedrich Ebert. 
PARKER, David Stuart

1995 "Los pobres de la clase media: Estilo de vida, consumo e identidad en una ciudad tradicional" en: Aldo Panfichi H. y Felipe Portocarrero S. (eds.), Mundos interiores: Lima 1850-1950; pp. 161-185. Lima: Universidad del Pacífico, Centro de Investigación.

PATTNAYAK, Satya R. (ed.)

1996 Globalization, Urbanization, and the State: Selected Studies on Contemporary Latin America. Lanham, Md.

PIAZZA, María del Carmen

1999 "Prácticas ciudadanas en espacios urbanos del Perú. Organizaciones sociales y gobiernos locales en los noventa" en: Elsa Bardález, Martín Tanaka y Antonio Zapata (ed.), Repensando la política en el Perú; pp. 59-82. Lima: PUC, UP, IEP.

POLANY, Karl; ARENSBERG, Conrad M. y PEARSON W. H (ed.)

1957 Trade and Market in the Early Empires. Glenco: The Free Press.

PORTOCARRERO MAISCH, Gonzalo (ed.)

1993 Los nuevos limeños: sueños, fervores y caminos en el mundo popular. Lima: SUR-Casa de Estudios del Socialismo.

REMY, María Isabel

1994 "The Indigenous Population and the Construction of Democracy in Peru" en: Donna Lee Van Cott (ed.), Indigenous Peoples and Democracy in Lation America. New York: St. Martin's Press.

ROBERTS, Bryan R.

1995 The Making of Citizens: Cities of Peasants Revisited. London; New York; Sidney. ROGERS, Alisdair y VERTOVEC, Steven

1995 The Urban Context: Ethnicity, Social Networks, and Situational Analysis. Oxford; Washington, D. C.

ROSNER, Waltraud

1995 De migrantes a creadores de un distrito industrial: El caso de los pequeños productores de calzado en El Porvenir, Trujillo, Perú. Espacio y Desarrollo 5(7): 5-42.

ROTENBERG, Robert Louis y MACDONOGH, Gary W.

1993 The Cultural Meaning of Urban Space. New York: Bergin \& Garvey.

SASSEN, Saskia

1994 Cities in a World Economy. Thousand Oaks; London; New Delhi.

1996 Whose City Is It? Globalization and the Formation of New Claims. Public Culture 8: 205-223.

SKAR, Sarah Lund

1994 Lives Together-Worlds Apart: Quechua Colonization in Jungle and City. Oslo: Scandinavian University Press. (Oslo Studies in Social Anthropology.

SOUTHALL, Aidan (ed.)

1973 Urban Anthropology. Cross Cultural studies of Urbanization. London; Toronto: Oxford University Press. 
STEINHAUF, Andreas

1991 Diferenciación étnica y redes de larga distancia entre migrantes andinos: El caso de Sanka y Colcha. Bulletin de l'Institut Français d'Etudes Andines 20(1): 93-114.

STRÖBELE GREGOR, Juliana

1993 Búsqueda de seguridad y de formas propias de afirmación de la identidad social aymara urbana. Cuenca.

TANAKA, Martín

1995 "Jóvenes: actores sociales y cambio generacional. De la acción colectiva al protagonismo individual" en: Julio Cotler (ed.), Perú 1964-1994. Economía, Sociedad y Política. Lima: IEP.

WALDMANN, Adrián

2008 El hábitus camba. Estudio etnográfico sobre Santa Cruz de la Sierra. Santa Cruz de la Sierra: Editorial El País (Colección Ciencias Sociales 12).

WALLACE, James Macauly

1984 Urban Anthropology in Lima: An Overview. Latin American Research Review 19(3): $57-85$. 